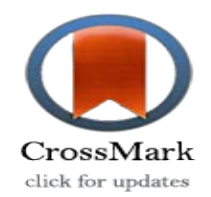

\title{
Health related needs of the elderly in Sabzevar city of Iran , 2019
}

\author{
Samane Gholizadeh', Zahra Estaji ${ }^{2}$, Rahim Akrami ${ }^{3}$ *Akram Ghanbari \\ Moghaddam $^{4}$
}

\begin{abstract}
1- MSc of Geriatric Nursing, Faculty of Nursing \& Midwifery, Sabzevar University of Medical Sciences, Sabzevar, Iran.

2- Nursing Instructor, Iranian Research Center on Healthy Aging, Sabzevar University of Medical Sciences, Sabzevar, Iran.

3- MSc of Epidemiology, Department of Epidemiology \& Biostatistics, School of Public Health, Sabzevar University of Medical Sciences, Sabzevar, Iran

4- Faculty of Nursing and Midwifery School, Mashhad University of Medical Sciences, Khorasan-e Razavi, Mashhad, Iran (Corresponding Author)

E-mail: GhanbariMA@mums.ac.ir
\end{abstract}

Received: 6 Sep 2019

Accepted: 17 Jan 2020

\section{Abstract}

Introduction: Elderly people often have complex and unknown needs but we have not yet fully recognized them in accordance with international standards in our country. Therefore, the present study attempts to more accurately identify the types of fulfilled or unmet needs related to the health of the elderly in Sabzevar city using valid and specialized tools.

Methods: This descriptive cross-sectional study was performed on 240 elderly people over 60 years old without any cognitive problems in Sabzevar city in 2019. They were selected by Stratified sampling from population areas of 6 health centers in the city. Data were collected by a questionnaire consisting of two parts demographic and need assessment based on Cambrol standardized instrument (CANE) and were analyzed by Stata v.14 and statistical methods.

Results: The mean age of the study units was $68 / 1 \pm 7 / 2$. Based on the main findings of the study, the elderly with unmet needs ranked first in terms of benefits $(23 \%)$, physical health (16\%), medicine (15\%), money / budget (14\%), sight / hearing (10\%), Daily activities $(9.5 \%)$, nutrition $(9 \%)$, mobility $(9 \%)$, housekeeping $(8 \%)$, caring for another $(6 \%)$, mental comfort (5\%) and They have savings (5\%). On the other hand, the most fulfilled needs were medication (39\%), physical illness (35\%) and visual and hearing improvement (28\%).

Conclusions: The results of the present study showed that the most unmet needs of the elderly were physical and then social needs and environmental needs were the least priority for them.

Key Words: Needs Assessment, Aged, Health. 


\title{
شناسايى نياز هاى مرتبط با سلامت سالمندان شهر سبزوار در سال
}

\author{
سمانه قلى زاده'، زهرا استاجى '، رحيم اكرمى"، ،*اكرم قنبرى مقدم
}

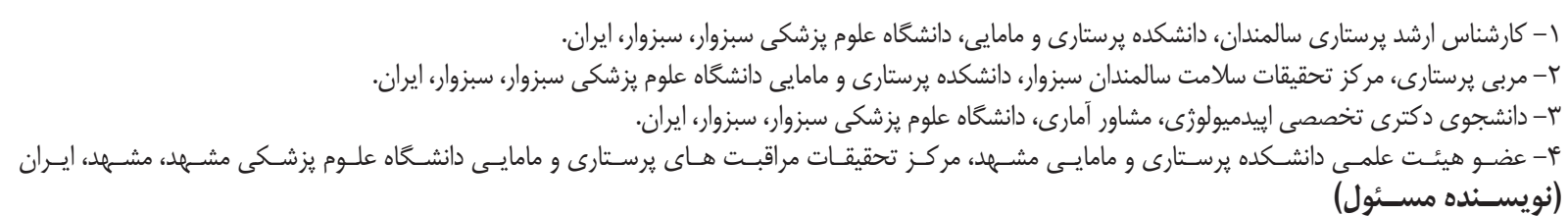

ايميل:GhanbariMA@mums.ac.ir

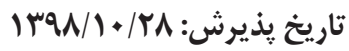

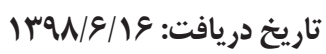

جكيده

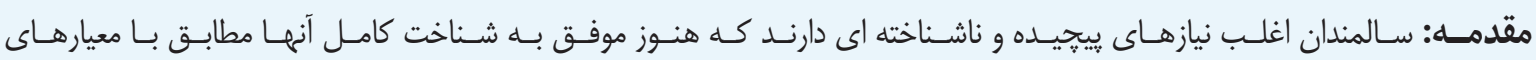

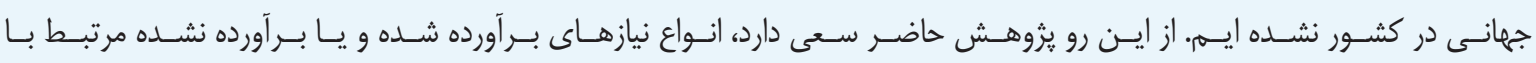

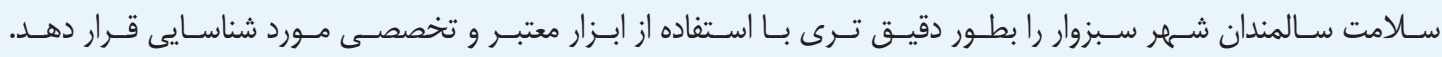

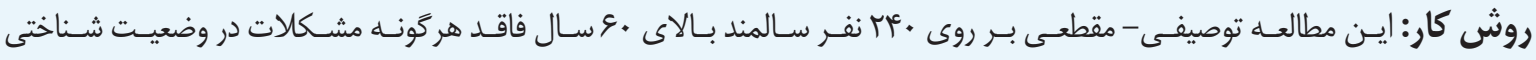

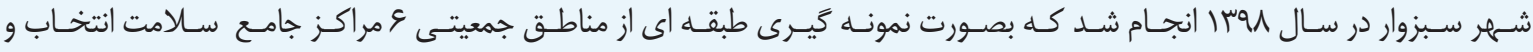

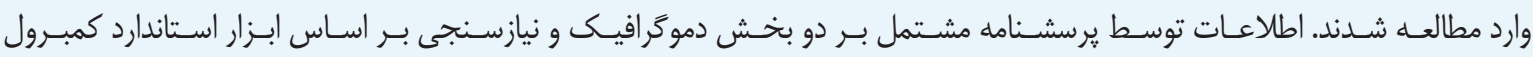

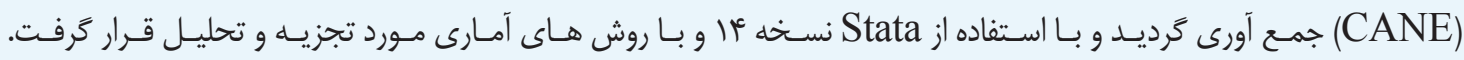

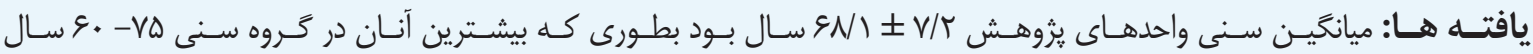

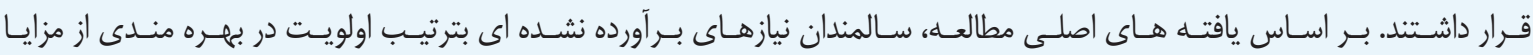

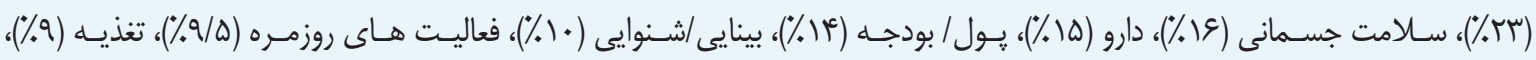

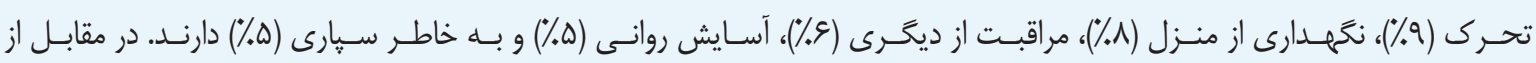

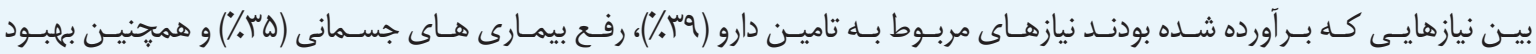

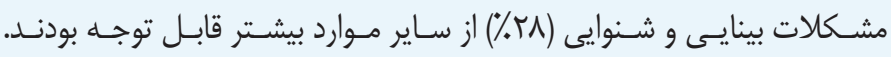

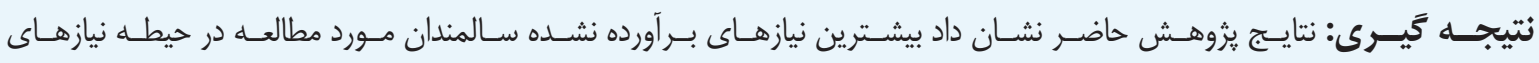

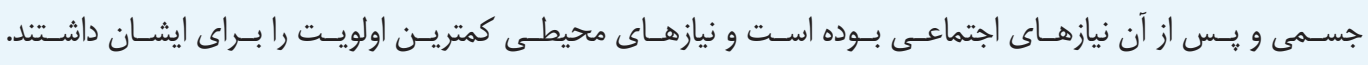
كليدوازه ها: نيازسنجى، سالمندان، سلامت.

منظــور ترويـج سـالمندى فعـال و موفـق در آنـان هـر روز ابعـاد

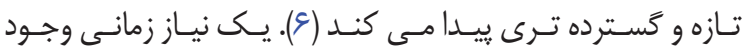

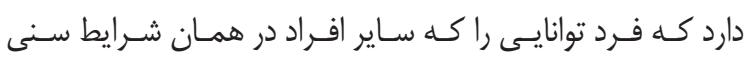

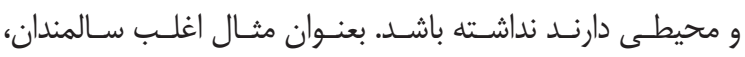

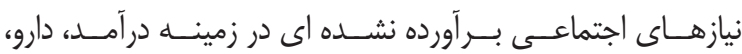

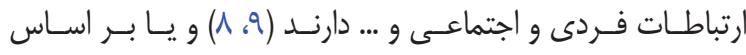

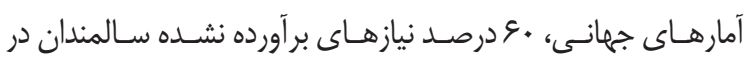

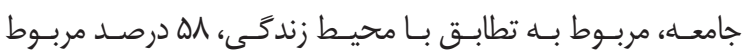

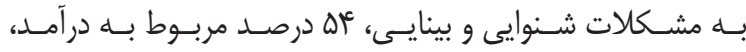

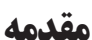

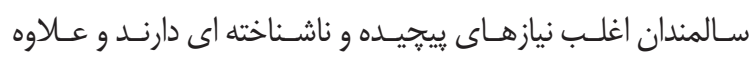

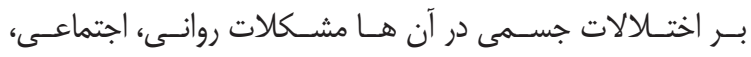

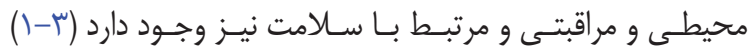

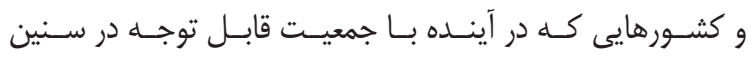

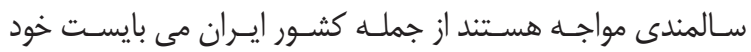

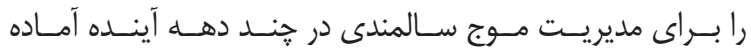

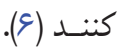
بحـث بــرآورده كـردن نيازهـاى خــاص سـالمندان جامعـه بــهـ 


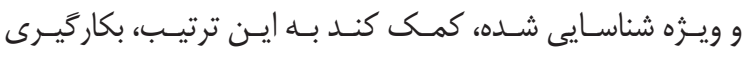

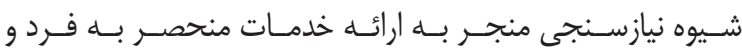

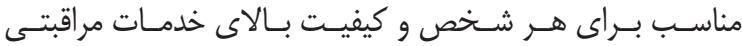

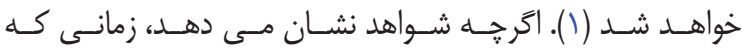

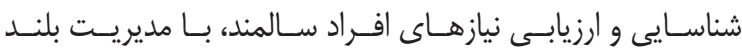

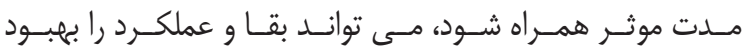

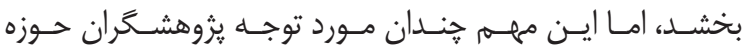

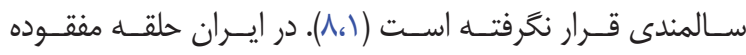

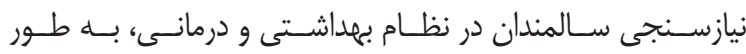

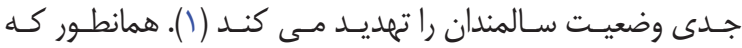

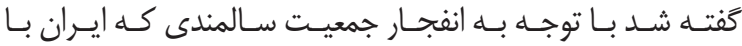

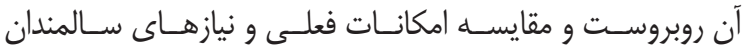

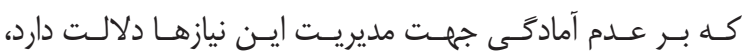

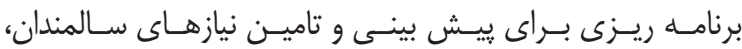

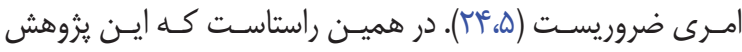

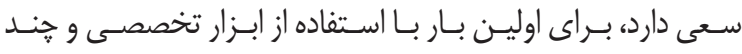

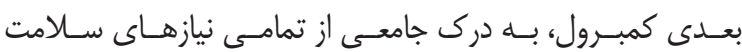

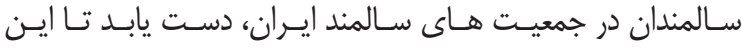
مســائل بــه طــور واقعسى و از نزديـك بررسـى شــند.

\section{روش كار}

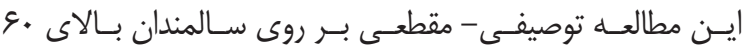

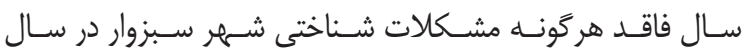

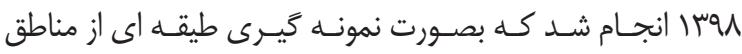

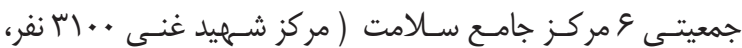

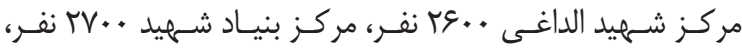

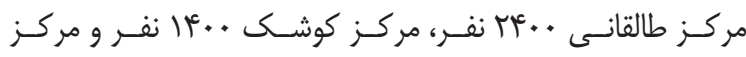

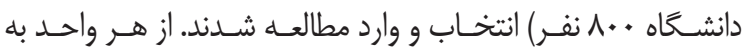

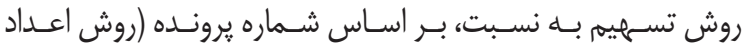

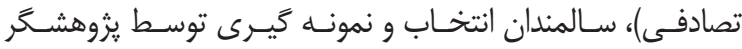

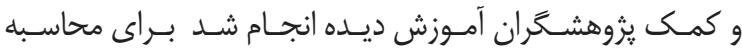

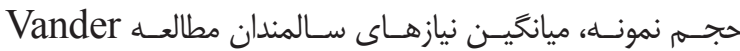

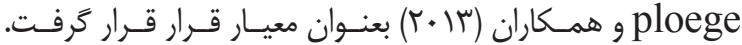

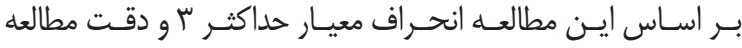

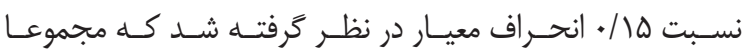

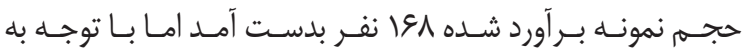
ريـزش •ب درصـدى در مطالعـات كذشـته (9) كل حجـم نمونسه

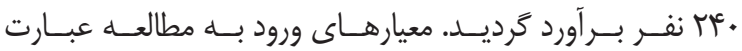

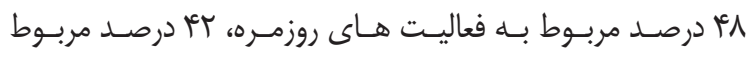

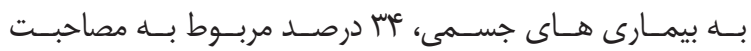

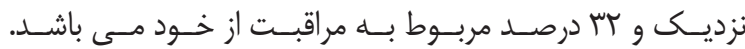

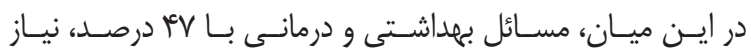

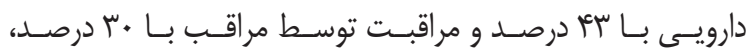

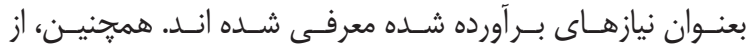

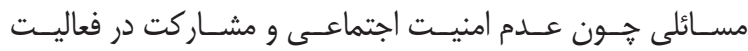

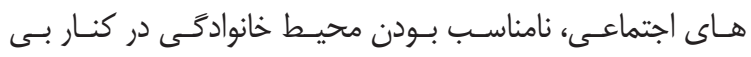

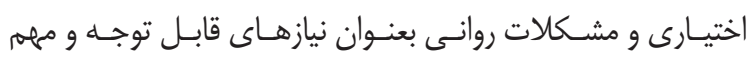

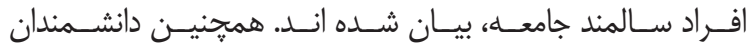

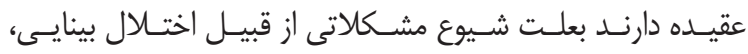

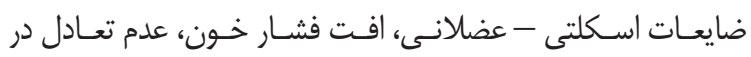

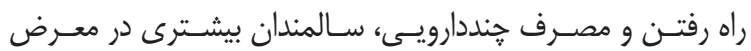

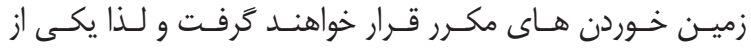

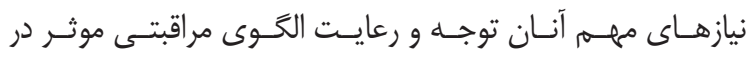

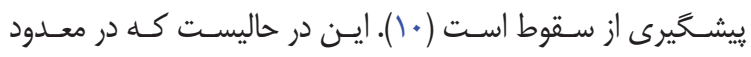

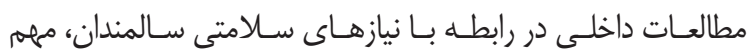

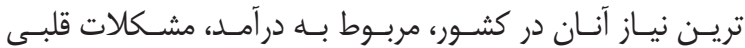

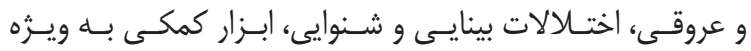

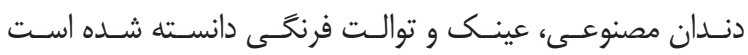

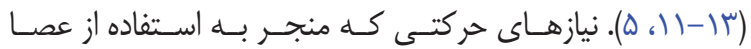

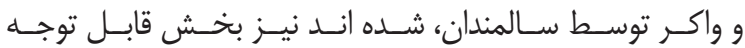

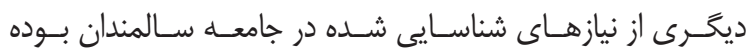

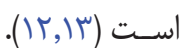

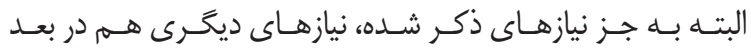

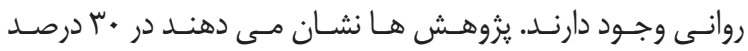

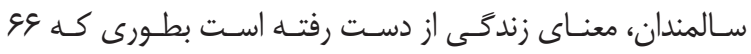

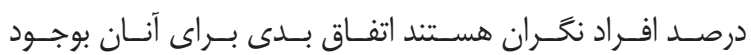

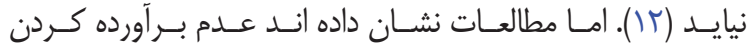

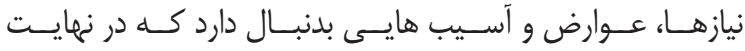

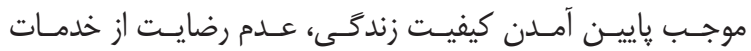

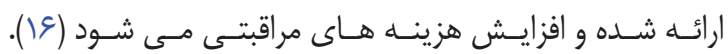

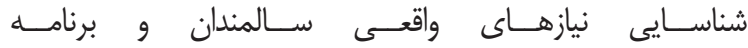

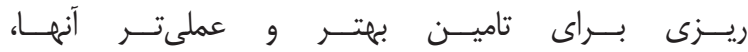

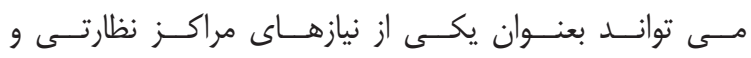

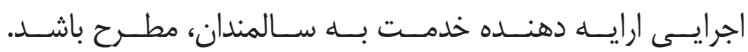

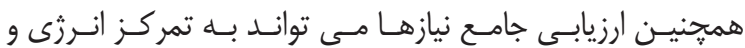

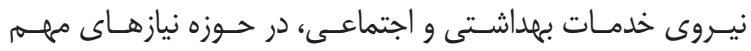




\section{سمانه قلى زاده و همكاران}

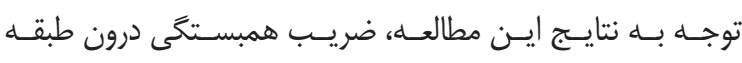

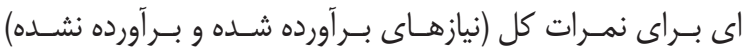

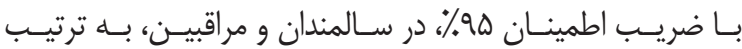

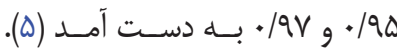

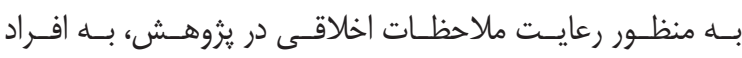

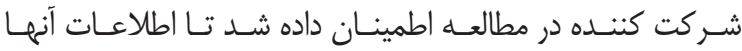

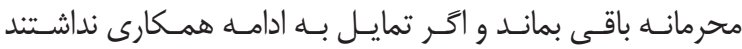

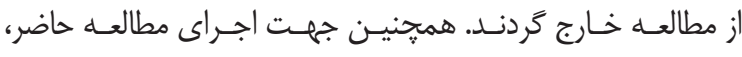

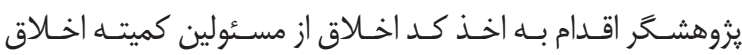

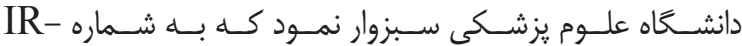

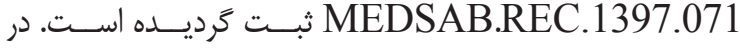
نهايـت اطلاعـات جمـع آورى شـــه بـا اسـتفاده از SPSS نسـخهـ

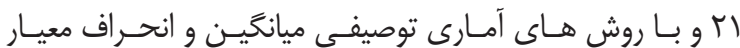
مـورد تجزيـه و تحليـل قـرار زرفـت. سـطح معنسى دارى در كليـهـ

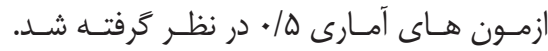

\section{يافته ها}

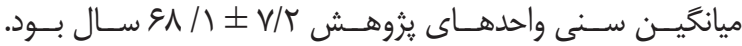

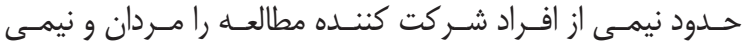

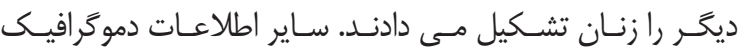

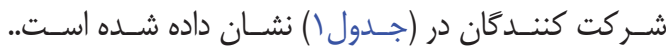

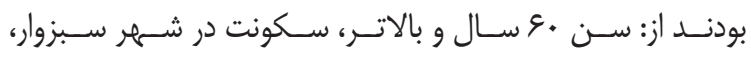

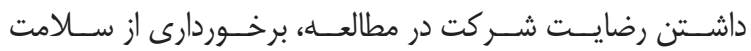

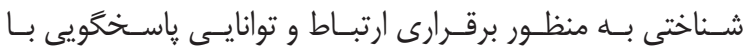

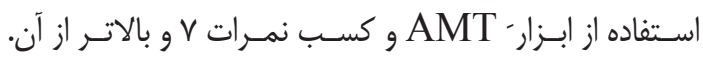

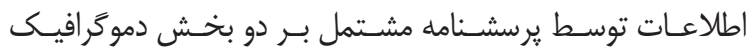

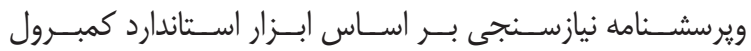

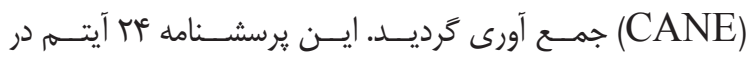

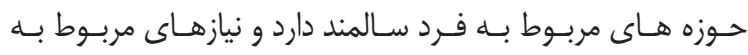

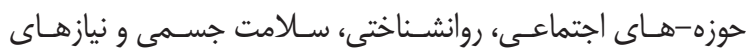

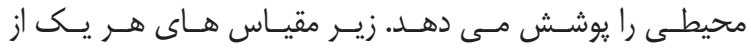

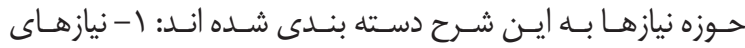
محيطى سـالمندان: محــل ســونت، مواظبـت از خانــه، امنيــت

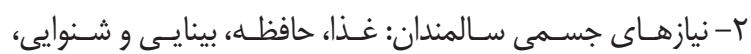

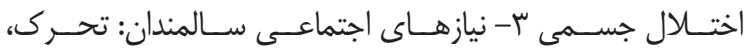

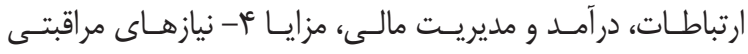

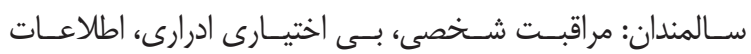

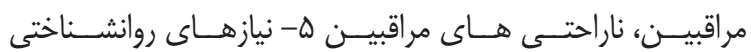

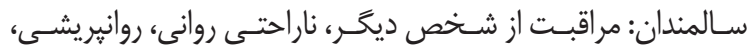

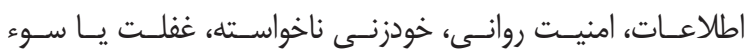

اسـتفاده، الـكل، مصاحبـت (ه).

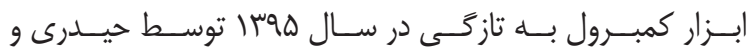

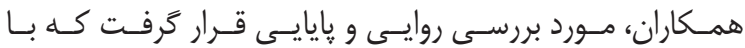

جدول ( : واحدهاى شركت كننده در مطالعه به تفكيك مشخصات دموگر افيك

\begin{tabular}{|c|c|c|c|}
\hline تعداد ( درصد ) & متغير & تعداد ( درصد ) & 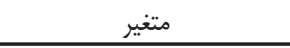 \\
\hline$(r / \cdot \Lambda) \Delta$ & مجرد & & \\
\hline$(\varepsilon \backslash / T \Delta) \mid f V$ & متاهل & $(0 . / 9) 1 T r$ & زن \\
\hline ( & مطلقه & $(5 q / 1) 111$ & 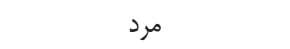 \\
\hline . & همسرفوت شده & $(r \Delta / \Delta \cdot) \Delta F$ & بى سواد \\
\hline$(r \Delta)^{q}$. & زندَّى در تنهايى & $(\Delta V / \Delta \cdot) \mid r \Lambda$ & تحصيلات ابتدايى \\
\hline$(F V / q T) \| D$ & زندگى با همسر و فرزندان & $(1 r / \wedge) r q$ & داراى سيكل يا دييلهم \\
\hline$(I r / \Delta \cdot)^{\mu} \cdot$ & زندگى با فرزندان & $(V / 9 T) 19$ & تحصيلات دانشخاهى \\
\hline$(I r / q T) M I$ & زندگى با آشنايان & (\&) YFD & ابتلا به بيمارى زمينه اى \\
\hline$(\cdot 1 / 9 V)^{F}$ & زندگى در سراى سالمندان & $(1 F) \Delta V$ & عدم ايتلا به بيمارى زمينه اى \\
\hline $9 N / 1$ & متوسط سن شركت كنندكان & & \\
\hline
\end{tabular}

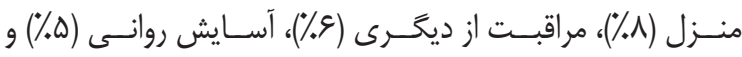

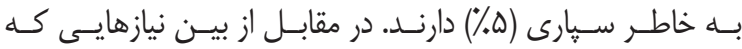

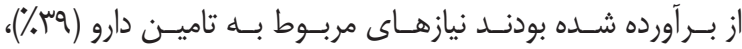

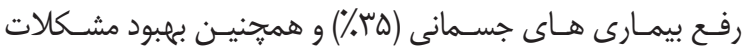

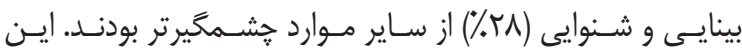

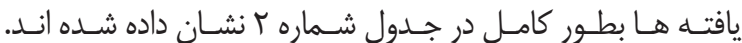

در ادامـه يثزوهـش، يافتـه هــاى حاصـل از يرسشــامه نيازسـنجى

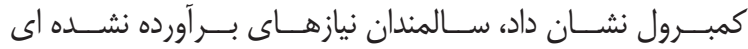

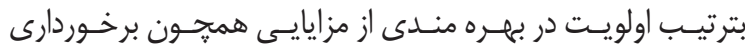

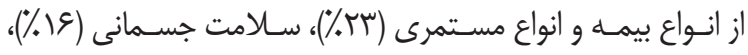

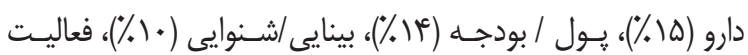

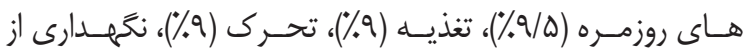


جدول r: توزيع فروانى نياز هاى مرتبط با سلامت سالمندان شهر سبزوار

\begin{tabular}{|c|c|c|c|c|c|c|}
\hline \multicolumn{2}{|c|}{ نياز برآورده نشده } & \multicolumn{2}{|c|}{ نياز برآورده شده } & \multicolumn{2}{|c|}{ عدم نياز } & \multirow{2}{*}{ حيطه هاى نيازهاى مرتبط با سلامت سالمندان } \\
\hline درصد & فراوانى & درصد & فراوانى & درصد & فراوانى & \\
\hline$\Delta / \wedge \varepsilon$ & $1 f$ & $r / q \mu$ & V & $91 / \pi)$ & $r M$ & محل سكونت \\
\hline$V / \Delta T$ & 11 & $\mid \varepsilon / V^{e}$ & f. & $V \Delta / V \pi$ & $|\wedge|$ & 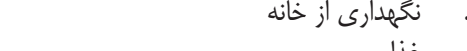 \\
\hline $9 / \pi 1$ & tr & $1 \% / r q$ & Tr & $V V / A^{4}$ & IND & \\
\hline$\varepsilon / r \Delta$ & 10 & 1. & MF & $\Lambda^{*} / \& \varepsilon$ & $r \cdot 1$ & مراقب \\
\hline$\varepsilon / \pi \Delta$ & 10 & $\Delta$ & ir & $\Lambda V / q T$ & rII & مراقبت | مرات \\
\hline $9 / 94$ & سז & $\Delta / \wedge \varepsilon$ & 14 & $\Lambda F / \Delta r$ & $r \cdot r$ & فعاليت هاى روزانه \\
\hline$\Delta / R T$ & سו & 1. & TF & $\Lambda F / \Delta \Lambda$ & $r \cdot r$ & حافظه \\
\hline $1 . / 48$ & TQ & TV/GT & 99 & $91 / 94$ & $1+1$ & بينايى \\
\hline$\Lambda / \wedge \varepsilon$ & rI & س & TE & $11 / \cdot 1$ & 194 & تحر \\
\hline$r / .9$ & $\Delta$ & $\Delta / \cdot r$ & it & $9 \% / 19$ & Trt & بع اختّ \\
\hline $10 / 9 V$ & щ & $r F / \Lambda V$ & ז & $19 / 19$ & $11 \mathrm{~V}$ & إ) \\
\hline$|0| \cdot 9$ & عץ & $\lceil N / 9 \mid$ & צ & س.|.|ع| & 11. & ل ال. ماروها \\
\hline$\cdot / A F$ & r & . & 1 & $q \wedge / V^{c}$ & عسז & ا. .علام روانيريشى \\
\hline$\Delta / \cdot F$ & 14 & $q / T F$ & Tr & $\Lambda \Delta / \checkmark 1$ & $r \cdot r^{r}$ & ا. . ناراحتى هاى روانى \\
\hline$r / .9$ & $\Delta$ & V/ar & M & $q \cdot / \mu$ & rIs & ا. ا. اطلاعات \\
\hline . & 1 & • & - & $99 / \Delta 1$ & r & ا. خودزنى عمدى \\
\hline$r / .9$ & $\Delta$ & ./AF & r & $9 \mathrm{~V} / \cdot \mathrm{V}$ & TrT & ا. خودزنى ناخواسته \\
\hline$\mu / \mu \Delta$ & $\wedge$ & $r / . q$ & $\Delta$ & $q \tau / \Delta \%$ & Tre & ا. سواستفاده/ غفلت \\
\hline 1.1 .4 & te & $1 / T \varepsilon$ & r & $\mathrm{MN} / \mathrm{V}$. & rIT & لـ رقتار ( دركيرى \\
\hline . & - & • & . & $1 \ldots$ & 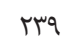 & ז'. سوءمصرق دارو ي \\
\hline $1 / \pi 9$ & $\mu$ & - / $\lambda F$ & $r$ & $q \vee / q$. & שחו & r. \\
\hline $1 / 8 \Lambda$ & f & $\cdot / \Lambda f$ & r & $9 \vee / 4 \wedge$ & זמז & ז'. أرتباطات صميمى \\
\hline $1 \% / 94$ & 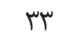 & $N \cdot r$ & 19 & $\mathrm{VN} / \cdot \mathrm{G}$ & IND & ז' يول/ بود \\
\hline$r \mu / .1$ & $\Delta \Delta$ & $r / V$ & 9 & $V T / K T$ & IVD & 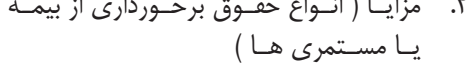 \\
\hline
\end{tabular}

نمسى شـود امـا بــا كزارشــات جهانسى همخوانسى نــارد. مثـلا

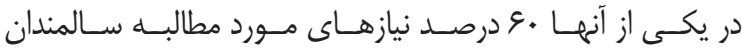

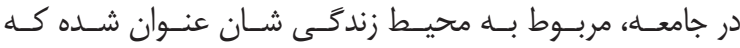

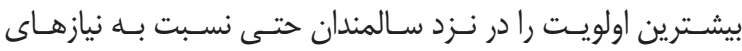

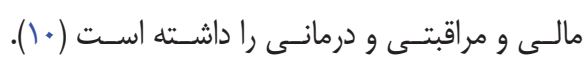

نتايسج كلـى مــا مبنـى بــر اولويست و نيــاز جـــى تــر در حيطـهـ

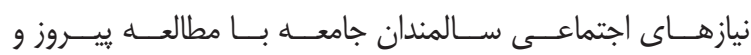

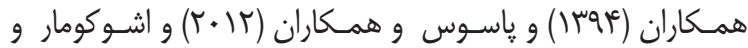

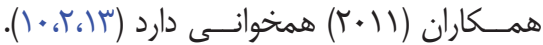

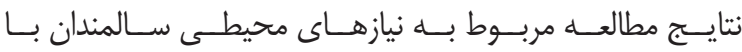

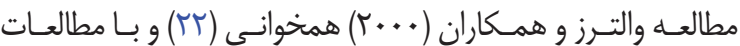

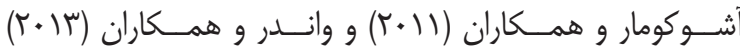
ناهمخوانسى داشـت (•(19). علـت ناهمخوانسى را مسى تسوان

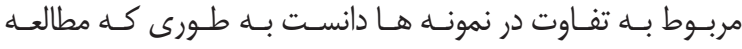

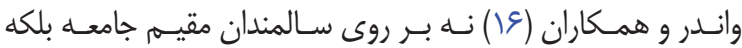
بـر روى سـالمندان مقيـم سـراهاى سـالمندان انجـام شـــه بــود و محيـط يثزوهـش آشـوكومار و همــكاران (• (1) نيـز ســالمندان

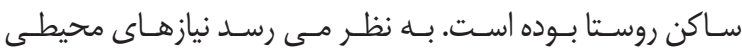

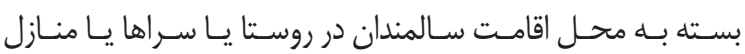

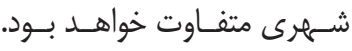

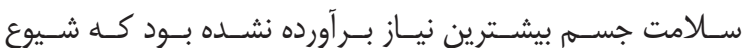
همجنيـن نتايسج كلـ يزوهــ حاضـر مبنسى بـر تاميـن بـودن

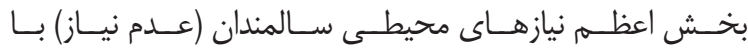

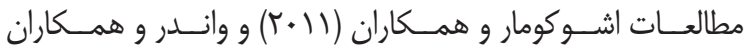

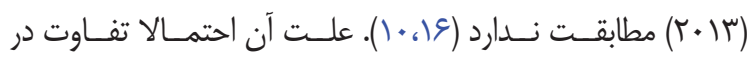
محـل اقامـت سـالمندان در مطالعـات مذكـور بـوده اسـت كــهـ

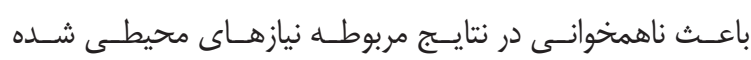

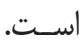

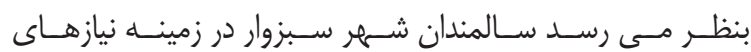

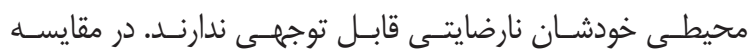

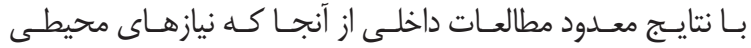
مشـابه و يـا خاصسى را بعنـوان اولويـت نيازهـاى مدنظر سـالمندان

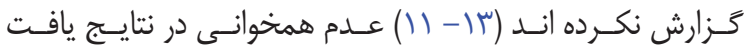




\section{سمانه قلى زاده و همكاران}

تعـداد نمونـه هـا بطـورى كـهـ مطالعـه والتــرز ، سـالمندان بـالاى

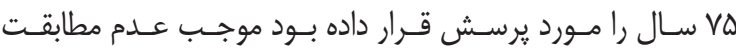

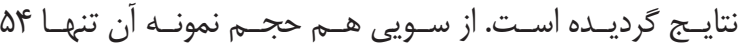
سـالمند بـود كـه قابليـت تعميـمم نتايسج آن را محـدود مسى سـازد. مشكلات و محدوديت هاى يزوهش

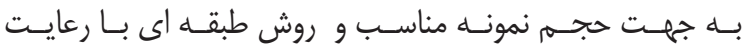
تسهميمه بــه نسـبت از مناطـق مختلـف شـهر قابليت تعميـهم نتايج مطالعهـ حاضـر را افزايـش داده و بكاركيـــى ابزار اسـتاندارد جهانى

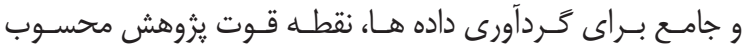

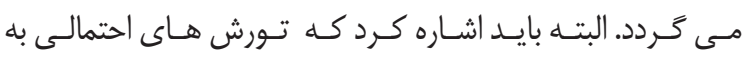
سـبب شـرايط روحسى و روانسى افـراد سـالمند در ياسـخكويى بـهـ

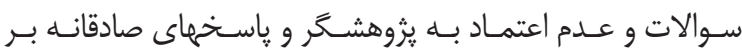

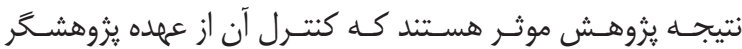

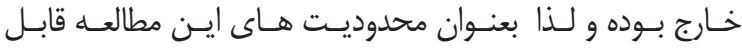

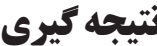

در بروهـش حاضـر، سـالمندان در شهمر ســـزوار نيازهـاى بـرآورده

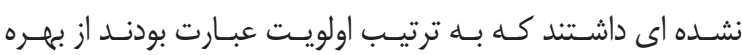

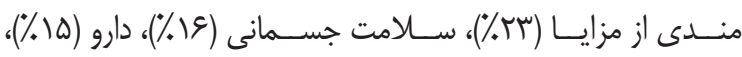

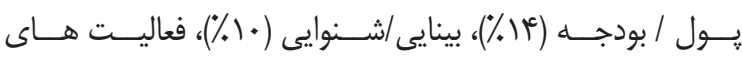

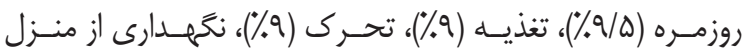

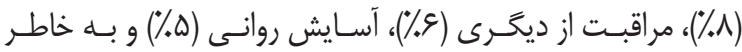

سـبارى در حافظـهـه (ه\%). نتايـج يزوهـش حاضــر نشـان داد بيشـترين نيازهــاى بــرآورده

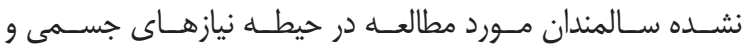

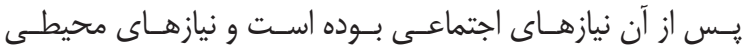
كمتريـن اولويــت را بــراى ايشـان داشـتند.

\section{تشكر و قدردانى}

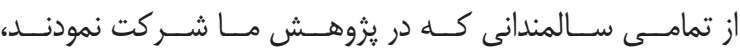
همجنيـن مديــران و مســولين و اسـاتيد در دانشـكده يرسـتارى

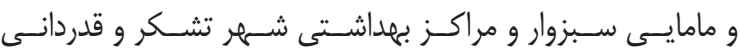

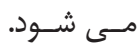

عا درصـــى داشــت. بديـن معنـى كــهـ ايــن تعــداد افــراد

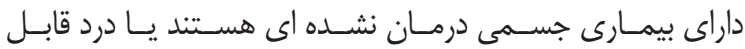

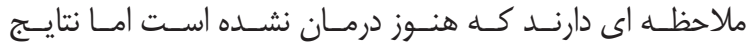
يثروهـش يِيـروز و همــاران نشـان مسى دهـــ دو سـوم سـالمندان

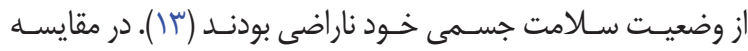
نتايسج بـه نوعى همخوانسى ديــده مسى شـود از ايـن منظـر كـهـ

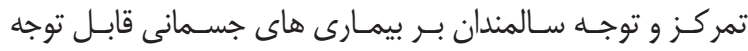

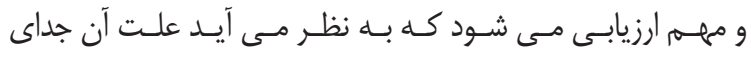

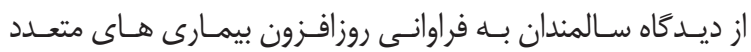

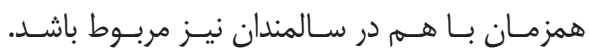
نيازهـاى اجتماعسى ســالمندان در ايـن مطالعـه از بررسـى يافتـهـ

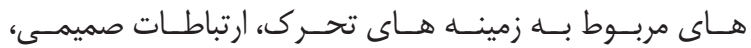

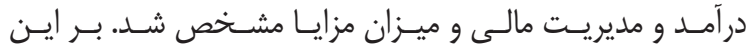

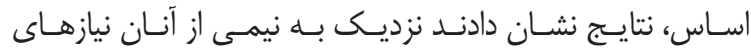

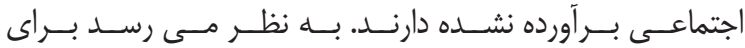

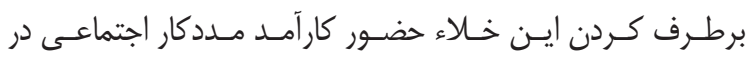

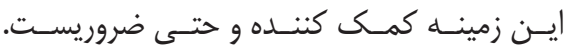

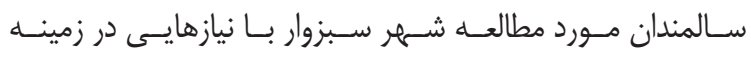

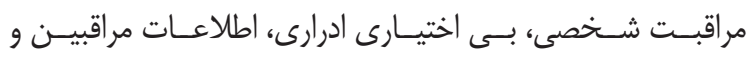

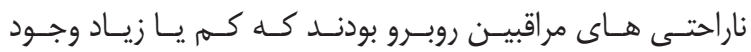

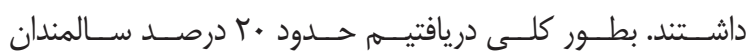

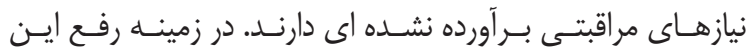

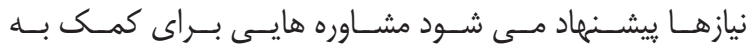

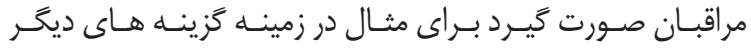

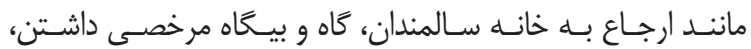
در حَروه هــاو انجمـن هـاى حمايتـى از مراقبـان شـركت داشـتن

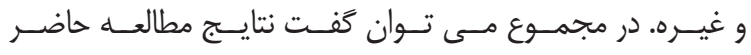

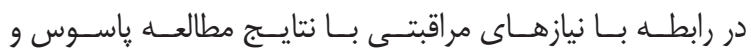

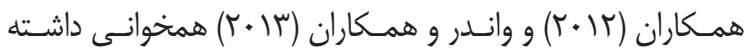

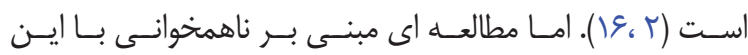

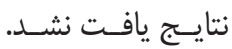

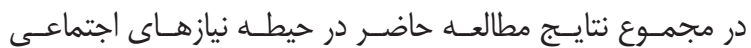

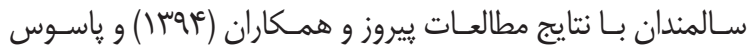

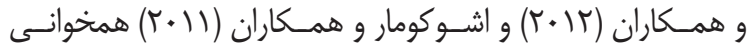

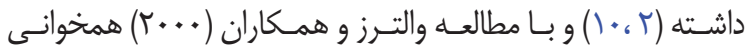

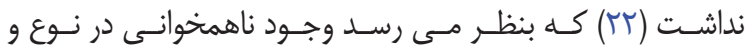




\section{Refrences}

1. Reynolds T, Thornicroft G, Abas M, Woods B, Hoe J, Leese M, et al. Camberwell Assessment of Need for the Elderly (CANE). Development, validity and reliability. The British journal of psychiatry: the journal of mental science 2000.176: 444 - 52.

2. Passos J, Sequeira C, Fernandes L. The Needs of Older People with Mental Health Problems: A Particular Focus on Dementia Patients and Their Carers. International Journal of Alzheimer's Disease. 2012; 2012: 7.

3. Sultan S, Classen D, Stansfeld S. Older People with Long-term Mental Illness: A Survey in a Community Rehabilitation Services Using the Camberwell Assessment of Needs for the Elderly. British Journal of Medical Practitioners. 2011;4(4):438-42.

4. Shakeri Nia Iraj. The Relationship between Social Support and Hope with General Health in the Elderly Man with Chronic Physical pains. Guilan University of Medical Sciences Journal. 2008.

5. Heidari $\mathrm{M}$ et al. Study of the validity and repeatability of the Persian version of the Camberwell Needs Test in the Iranian elderly. Thesis for obtaining a master's degree. Jundishapur University of Ahvaz. 2017.

6. Rasel M, Ardalan A. The Future of Ageing and Its Health Care Costs: A Warning for Health System. Iranian Journal of Ageing. 2007; 2 (2):300-5.

7. Iran AC. Statistical Central Of Iran. 2017 ed. iran: Aveilable et al www://amar.org.ir; 2017. p. 17-20

8. Smith F, Orrel M. Does the Patient-centred Approach Help Identify the Needs of Older People Attending Primary Care. Age \& Ageing 2007; 36: 628-31.

9. Miranda-Castillo C, Woods B, Galboda K, Oomman S, Olojugba C, Orrell M. Unmet needs, quality of life and support networks of people with dementia living at home. Health and Quality of Life Outcomes. 2010;8 (1): 132.

10. Ashokkumar T TV, Chacho \& Suresh M. Health Care and Social Needs of The Elderly: Assessed by the Tool Camberwell Assessment of Need for the Elderly. International Journal of Tropical Medicine. 2011;6 (5): 97-9.
11. Mohagheghi Kamal SH, Sajadi H, Zare H, Biglarian A. Need Assessment Among the Elders of Social Security Organization \& National Retirement Fund. Iranian Journal of Ageing. 2008; 3 (1): 8-15.

12. Malek Afzali H, Eftekhary Baradaran M, Hejazi F, Tabriz R, Faridi T. Community mobilization to promote the health of the elderly in the neighborhood Complex Tehran. Hakim. 2007; 1 (4).

13. Pirouz F, Mohammadi Shahbolaghi F, Foroughan M. Prevalence of Physical Diseases and Disorders in Retired Armed Forces; a Case Study of Tehran City, Iran. Iranian Journal of War and Public Health. 2017; 9 (1): 53-60.

14. Delpisheh A, Kohi Ardebili S, BaBanejad M, Mansorian M, Ghorbani M, Rezapor A, et al. Survey of Health Status and Health Needs of the Elderly in1 Ilam Province\%J Tolooebehdasht. 2016;14 (5): 1-14.

15. Madah SB. The Status of Social and Leisure Time Activities in the Elderly Residing In Iran and Sweden. Iranian Journal of Ageing. 2008; 3 (2):597-606

16. van der Ploeg ES, Bax D, Boorsma M, Nijpels G, van Hout HP. A cross-sectional study to compare care needs of individuals with and without dementia in residential homes in the Netherlands. BMC Geriatrics. 2013; 13 (1): 51.

17. Van der Roest H, Meiland, F., Van Hout, H., Jonker, C., \& Dröes, R. Validity and reliability of the Dutch version of the Camberwell Assessment of Need for the Elderly in communitydwelling people with dementia. International Psychogeriatrics. 2008; 20 (6): 1273-90.

18. Sousa RM, Scazufca M, Menezes PR, Crepaldi AL, Prince MJ. Feasibility and reliability of the elderly version of the Camberwell Assessment of Needs (CANE): results from the Sao Paulo Ageing \& Health Study. Revista brasileira de psiquiatria (Sao Paulo, Brazil: 1999). 2009; 31 (1): 34-8.

19. Keshavars $\mathrm{MN}$ et al. etermining the health needs of the citizens of Tehran and presenting its recommendations, a combined study. Thesis for obtaining MPH degree in aging of Tehran University of Social Welfare and Rehabilitation Sciences. 2017. (persian).

20. Montazeri A, Goshtasebi A, Vahdaninia M, 
Gandek B. The Short Form Health Survey (SF-36): translation and validation study of the Iranian version. Quality of life research: an international journal of quality of life aspects of treatment, care and rehabilitation. 2017; 14 (3): 875-82.

21. Hancock G OM. The Camberwell Assessment of Needs for the Elderly (CANE) Manual. London. Gaskell. 2004: PP: 83-115.

22. Walters K, Iliffe S, Tai SS, Orrell M. Assessing needs from patient, carer and professional perspectives: the Camberwell Assessment of Need for Elderly people in primary care. Age and Ageing. 2000; 29 (6): 505-10.

23. Abi Habib L CH, Developing Capacities in Ageing Studies in the MiddleEast: Implementation of an Arabic Version of the CANE-IV among Community-dwelling Older Adults in Lebanon. Ageing \& Mental Health. 2011; 15 (5): 605 - 17.

24. Shoaei F, Nejati V. Elderly-Caring Service Pattern in USA Comparing With Iran. Iranian Journal of Ageing. 2008; 3 (1): 68-77.

25. Mohammadi $M$ et al. Referral status and demographic characteristics of elderly patients in emergency departments in Sabzevar, 2016.

26. Ghanbari Moghadam A, Mohammadi shahboulaghi F, Dalvandi A, Hossein Zadeh S. Relationshep Between Health and life Style in Elderly People in Tehran. Iranian Journal of Ageing. 2015; 10 (3): 90-9. 